\title{
Temporal scales of water-level fluctuations in lakes and their ecological implications
}

\author{
Hilmar Hofmann · Andreas Lorke · Frank Peeters
}

\begin{abstract}
Water-level fluctuations (WLF) of lakes have temporal scales ranging from seconds to hundreds of years. Fluctuations in the lake level generated by an unbalanced water budget resulting from meteorological and hydrological processes, such as precipitation, evaporation and inflow and outflow conditions usually have long temporal scales (days to years) and are here classified as long-term WLF. In contrast, WLF generated by hydrodynamic processes, e.g. basin-scale oscillations and travelling surface waves, have periods in the order of seconds to hours and are classified as short-term WLF. The impact of WLF on abiotic and biotic conditions depends on the temporal scale under consideration and is exemplified using data from Lake Issyk-Kul, the Caspian Sea and Lake Constance. Longterm WLF induce a slow shore line displacement of metres to kilometres, but immediate physical stress due to currents associated with long-term WLF is negligible. Large-scale shore line displacements change the habitat availability for organisms adapted to terrestrial and aquatic conditions over long time scales. Shortterm WLF, in contrast, do not significantly displace the
\end{abstract}

Guest editors: K. M. Wantzen, K. O. Rothhaupt, M. Mörtl, M. Cantonati, L. G. Tóth \& P. Fischer Ecological Effects of Water Level Fluctuations in Lakes

H. Hofmann $(\bowtie) \cdot$ A. Lorke $\cdot$ F. Peeters

Environmental Physics, Limnological Institute, University of Konstanz, Mainaustr. 252, 78465 Konstanz, Germany e mail: hilmar.hofmann@uni konstanz.de boundary between the aquatic and the terrestrial habitat, but impose short-term physical stress on organisms living in the littoral zone and on organic and inorganic particles deposited in the top sediment layers. The interaction of WLF acting on different time scales amplifies their overall impact on the ecosystem, because long-term WLF change the habitat exposed to the physical stress resulting from short-term WLF. Specifically, shore morphology and sediment grain size distribution are the result of a continuous interplay between short- and long-term WLF, the former providing the energy for erosion the latter determining the section of the shore exposed to the erosive power.

Keywords Water-level fluctuation - Waves . Remobilisation of particles - Shore formation . Habitat conditions · Littoral zone

\section{Introduction}

Water-level fluctuations (WLF) and their ecological and socio-economic consequences have been investigated in large lakes, e.g. Aral Sea (Usmanova, 2003; Zavialov et al., 2003), Lake Chad (Guganesharajah \& Shaw, 1984; Coe \& Foley, 2001), Great Salt Lake (Stephens, 1990) or Salton Sea (Bourne et al., 2005) and also in small lakes and reservoirs, e.g. (Hunt \& Jones, 1972; Coops et al., 2003; McGowan et al., 2005; Naselli-Flores \& Barone, 2005). The reasons 
and causes of WLF can be various: Hydrologically induced WLF are connected to climatic changes, changes in the constellation of large atmospheric pressure systems (North Atlantic and Southern Oscillation), or, most frequently, to seasonal variations in meteorological conditions. They can also be the result of anthropogenic use of water resources, as in the case of the Aral Sea (Usmanova, 2003). Hydrologically induced WLF are the result of a change in the water budget and, therefore, depend on the amounts of precipitation and evaporation, catchment size and characteristics, and on the discharge conditions (inflow versus outflow) of the basin. Prominent examples are Lake Constance (Luft \& van den Eertwegh, 1991; Jöhnk et al., 2004) or Lake Issyk-Kul (Brennwald et al., 2004). The time scales of the hydrologically induced WLF range from days to centuries (and even up to geological time scales) and will be referred to as long-term WLF throughout this paper. Wind forcing and ship traffic affect the surface-wave field and cause WLF on time scales on the order of seconds to hours. These hydrodynamically driven WLF are classified throughout this paper as short-term WLF.

Here, we present examples for WLF at different temporal scales from a physical oriented perspective and discuss their implication on the lake ecosystem with specific emphasis on the littoral zone. WLF are presented in an order of decreasing time scales, beginning with a time scale of centuries and ending with a time scale of seconds. Examples are taken from different lakes: Lake Issyk-Kul (Kyrgyzstan) for century scales, the Caspian Sea for decadal scales and Lake Constance for shorter time scales spanning years to seconds.

Long-term WLF and their ecological impacts are subject of a number of papers throughout this special issue. Here, we will put special emphasis on the discussion of short-term WLF. Often, the latter are not considered in the context of WLF, although they can have a major impact on the abiotic and biotic processes in the littoral zone. Several studies have investigated the impact of short-term WLF on coastal and shelf regions (Clark, 1997; Eriksson et al., 2004; Soomere, 2005; Erm \& Soomere, 2006). Only a few investigations, however, have focused on lake-littoral zones (Luettich et al., 1990; Eggleton et al., 2004; Scheifhacken, 2006). Information on short-term WLF are required for the understanding of shore formation, which is the result of the interaction between shortand long-term WLF. Furthermore, short-term WLF impose physical stress on aquatic and riparian plants and organisms. This stress varies with the properties of the substrate (e.g. sand or stones), which, in turn, is altered by long-term WLF moving the boundary of the aquatic habitat up or down the shore. Hence, short-term WLF are important for an understanding of the ecological consequences of long-term WLF for aquatic organisms living in the littoral zone.

In the following sections, we first provide information on the materials and the methods used in this study. Then we present data on long-term and on short-term WLF at the example of Lake Constance. The subsequent discussion is focused on the impact of long- and short-term WLF on the littoral ecosystem, and specifically emphasises the importance of the combined effect of both. In the final section we summarise the main conclusions of the paper.

\section{Materials and methods}

Daily readings of water levels at gauge Konstanz for the time period 18172005 were provided by the State Institute for Environment, Measurements and Nature Conservation Baden-Württemberg (LUBW). The water levels are measured relative to the reference level of the gauge (391.89 m a.s.l., level Amsterdam). The water level time series was corrected for reading errors between 1817 and 1825 (Jöhnk et al., 2004). Note that between 1817 and 1876 the resolution of water level readings was only $3 \mathrm{~cm}$, thereafter $1 \mathrm{~cm}$.

Short-term WLF were measured using a pressure sensor with a resolution of 0.1 mbar, corresponding to about $1 \mathrm{~mm}$ water level. Measurements were carried out in the western part of Upper Lake Constance at a site called Littoral Garden (LG; $\left.47^{\circ} 41^{\prime} 29^{\prime \prime} \mathrm{N}, 09^{\circ} 12^{\prime} 11^{\prime \prime} \mathrm{E}\right)$. The pressure sensor was deployed $1 \mathrm{~m}$ above the sediment at $2.02 .5 \mathrm{~m}$ water depth and measured at a sampling frequency of $16 \mathrm{~Hz}$ throughout the entire year 2005. Pressure is a direct measure of water level only under hydrostatic conditions. However, the assumption of hydrostatic conditions is valid only if the wave length of the WLF exceeds a critical wave length of about 20 times the local water depth. WLF generated by surface gravity waves usually have a wave length that is 
significantly shorter than this critical wave length. Hence, the calculation of water level and WLF from pressure measurements requires a correction for pressure attenuation that depends on the water depth, the depth of the sensor and the wave length (Kundu \& Cohen, 2002; Hofmann et al., 2008). In the procedure wave length was calculated from wave frequency using the approximation to the dispersion relation of surface gravity waves by Fenton \& McKee (1990).

Maximum near-bottom current velocities generated by surface waves, $u_{\max }\left(\mathrm{m} \mathrm{s}^{-1}\right)$, were estimated using (Brown et al., 2005):

$u_{\max }=\frac{\pi \cdot H}{T \cdot \sinh \frac{2 \cdot \pi \cdot h}{\lambda}} \quad\left(\mathrm{m} \mathrm{s}^{1}\right)$

where $H$ denotes the wave height $(\mathrm{m}), h$ the water depth (m), $\lambda$ the wave length (m) and $T$ the wave period (s). The remobilisation of particles is related to $u_{\max }$ and can be determined from empirical equations. For non-cohesive sediments with a mean grain size $d_{50}$ between 0.063 and $2 \mathrm{~mm}$ (sand fraction) the formulation by Hallermeier (1980) was used to estimate the remobilisation of particles at $1 \mathrm{~m}$ water depth in the littoral zone of Lake Constance.

An Acoustic Doppler Velocity Meter (ADV) was deployed close to the pressure sensor at the site LG throughout the entire year 2005. The instrument measured the 3-dimensional current velocity $0.05 \mathrm{~m}$ above the sediment (at $12 \mathrm{~m}$ water depth) with a

Table 1 Temporal scales of WLF with the corresponding amplitudes and estimated maximum near bottom current velocities. Whereas long term WLF are generated by meteo sampling frequency of $8 \mathrm{~Hz}$. Current velocities associated with distinct frequencies (e.g. $54.6 \mathrm{~min}$ for the first-mode surface seiche in Lake Constance; see Table 1) were estimated using spectral analysis (Emery \& Thomson, 2001).

\section{Results}

\section{Long-term WLF}

In the following we analyse long-term WLF from Lake Constance, the second largest prealpine lake in Europe with a surface area of $536 \mathrm{~km}^{2}$ and a maximum water depth of $254 \mathrm{~m}$ (Braun \& Schärpf, 1990). Lake Constance and its main tributary, the river Rhine, are almost unregulated and the lake level shows a strong seasonal cycle. The level declines during winter and typically reaches the annual minimum at the end of February, when precipitation in the catchment area is, to a large extent, stored as snow. The lake level typically reaches an annual maximum in June/July due to increased snow melt in spring (Luft \& van den Eertwegh, 1991; Jöhnk et al., 2004). Long and intense precipitation in the catchment area in combination with snow melt can result in extreme floods with rapidly increasing water levels. Some examples of major flood events are marked in Fig. 1a. The relative height in the figure indicates the

rological and hydrological processes, short term WLF are generated by hydrodynamic processes

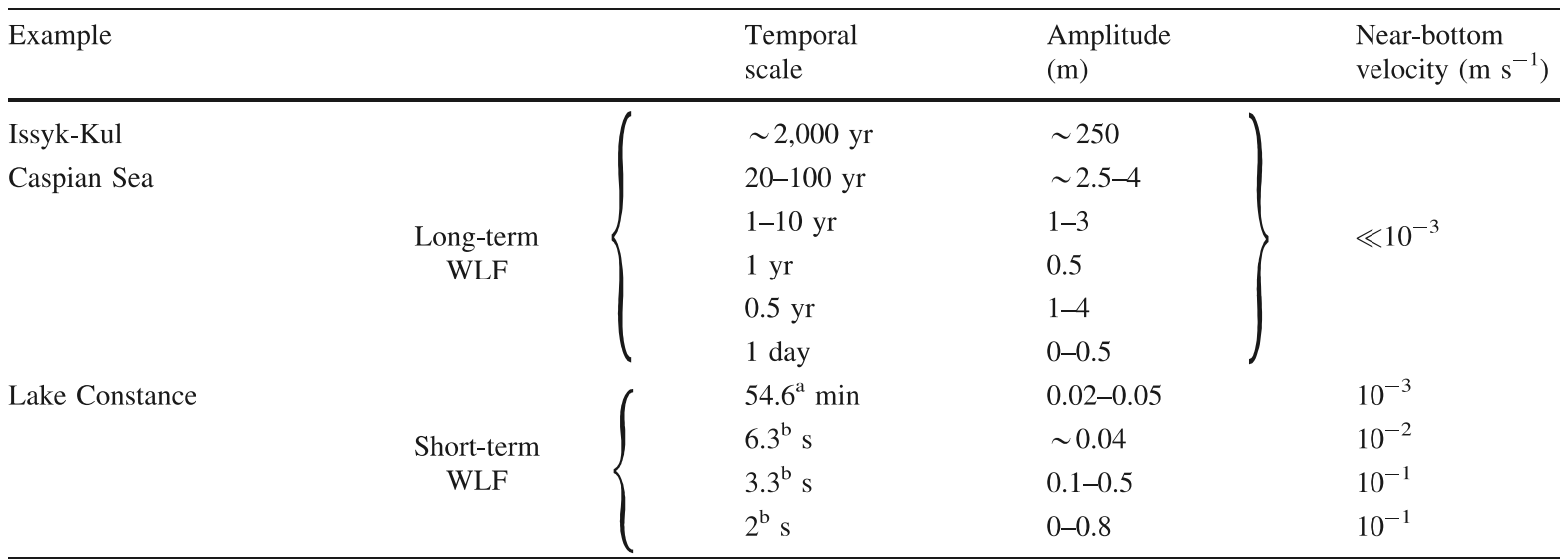

$\bar{a}$ Surface seiching and ${ }^{b}$ surface waves generated by fast catamaran ferries $(6.3 \mathrm{~s})$, passenger ships or ferries (3.3 s) and wind (2 s) measured at Lake Constance 
Fig. 1 Lake level time series at gauge Konstanz (Lake Constance) based on daily measurements from 1817 to 2005 . (a) Annual course of the maximum water levels. Major floods are marked by the individual year or period, whereas the height corresponds to the importance of the flood. (b) Mean annual water levels with linear regression line. (c) Seasonal variations within a single year (filled grey surface) determined as the difference between the maximum and minimum water level of the respective year. Linear regression lines emphasise the trend of the maximum and minimum water levels. The solid line fluctuating around zero shows the annual deviation from the mean of the seasonal WLF (over the whole time series) with its linear regression line. (d) Diurnal change of the water level shown as the difference between the daily mean values

importance of the events (Luft \& van den Eertwegh, 1991; Jöhnk et al., 2004). The greatest flood within the time period considered here was observed in 1817 with $623 \mathrm{~cm}$ above reference level. Other floods between 525 and $575 \mathrm{~cm}$ occur more frequently with an average recurrence time period of about $12 \mathrm{yr}$. Maximum water levels between 400 and $500 \mathrm{~cm}$ seem to be a regular range within the gauge Konstanz time series (Fig. 1a).

Linear regression reveals that the annual mean water level shows a significant long-term trend and declined by about $21 \mathrm{~cm}$ between 1817 and 2005 (slope: $-0.11 \pm 0.03 \mathrm{~cm} \mathrm{yr}^{-1}, P<0.01$; Fig. 1b). From 1817 to 1940 the annual mean water level shows no significant trend (slope: $0.008 \pm 0.05 \mathrm{~cm} \mathrm{yr}^{-1}, P=0.87$ ), but from 1941 to 1980 the level started to decrease (slope: $\left.0.12 \pm 0.14 \mathrm{~cm} \mathrm{yr}^{-1}, P=0.40\right)$. This decrease is even more pronounced during the last two and a half decades (slope: $-0.41 \pm 0.57 \mathrm{~cm} \mathrm{yr}^{-1}, P=0.48$ ) and is mainly caused by decreasing maximum water levels in summer. The reasons for the obvious break point around 1940 and the ongoing decline in water level has been widely discussed and was explained by changes in hydraulic discharge conditions and climatic changes in the catchment area (Luft \& Vieser, 1990; Jöhnk et al., 2004).

Inter-annual WLF, determined from the difference between the annual mean water levels of consecutive years (Fig. 1b), are about $20 \mathrm{~cm} \pm 17 \mathrm{~cm}$ (SD) on average. The maximum of the inter-annual WLF was $75 \mathrm{~cm}$ between 1921 and 1922 .

Seasonal WLF can be quantified by the difference of the minimum and maximum water level with respect to the mean water level of the particular year (Fig. 1c). Extreme seasonal WLF reach up to more than $300 \mathrm{~cm}$

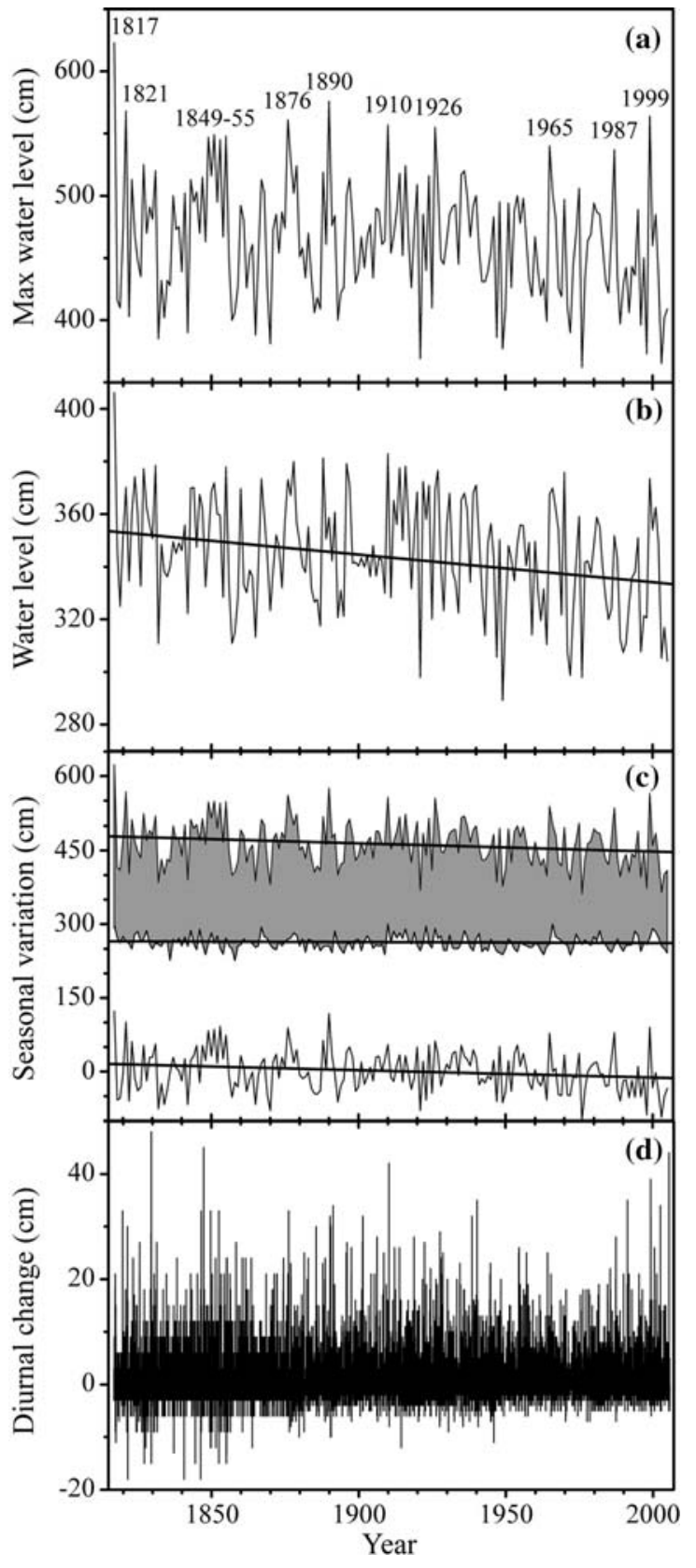

and occur in years with unusually high maximum water levels. The linear regressions of the annual maximum (slope: $-0.17 \pm 0.06 \mathrm{~cm} \mathrm{yr}^{-1}, P<0.01$, $\pm 45 \mathrm{~cm} \mathrm{yr}^{-1} \mathrm{SD}$ ) and minimum (slope: $-0.02 \pm 0.02 \mathrm{~cm} \mathrm{yr}^{-1}, P=0.33, \pm 14 \mathrm{~cm} \mathrm{yr}^{-1} \mathrm{SD}$ ) water level indicate a significant decline in the seasonal WLF from about $215 \mathrm{~cm}$ at the beginning of the 19th century to about $185 \mathrm{~cm}$ at the beginning of the 21st century (Fig. 1c). The long-term decline is 
caused by the decrease in the annual maximum water level, where in contrast the annual minimum water level remained constant. This also explains the observed trend of the annual deviation from the mean of the seasonal WLF (slope: $-0.15 \pm 0.06 \mathrm{~cm} \mathrm{yr}^{-1}$, $P<0.01, \pm 42 \mathrm{~cm} \mathrm{yr}^{-1} \mathrm{SD}$; Fig. 1c) which is mainly stated by the deviation of the annual maximum water level and, thus, shows the same significant decline. The decrease in the seasonal WLF especially during the last decades can be partly explained by the construction of hydropower reservoirs in the catchment (Luft \& van den Eertwegh, 1991; Jöhnk et al., 2004).

Over a single day, the water level can change by up to $40 \mathrm{~cm}$ (Fig. 1d). Such rapid increases in water level are always caused by extreme discharge events of the river Rhine resulting from intense precipitation in the catchment. Large water level increases continuing over several consecutive days can lead to major flood events (Luft \& van den Eertwegh, 1991). However, the typical daily decrease or increase in water level is much smaller than the extreme case mentioned above and typically ranges only from -5 to $10 \mathrm{~cm}$ (Figs. 1d, 2a).
Short-term WLF

Short-term WLF, at scales from seconds to hours, are mainly caused by hydrodynamic processes. In the following section we analyse high-frequency and high-resolution data of surface water level (estimated from pressure measurements) and current velocity from the littoral zone of Lake Constance. Single-day time series were chosen to explain the temporal variability of hydrodynamic processes on 17 and 26 January 2005 (Fig. 2a, b). Both days differ considerably due to different surface forcing generated by strong on-shore wind on 26 January 2005 and no wind on 17 January 2005.

A very prominent feature of enclosed water bodies are basin-wide oscillations of the surface level, often referred to as surface seiching (Mortimer, 1974; Lerman et al., 1995). The periods of such basin wide oscillations, called "modes", are determined by the morphology of the basin. The firstmode surface seiche in Lake Constance has a period of $54.6 \mathrm{~min}$ and can be seen in the running average applied to the surface level time series shown in
Fig. 2 High frequency $(16 \mathrm{~Hz})$ and high resolution (1 mm) measurements of the water level over a single day. (a) On 17 January 2005 under a no wind situation. (b) On 26 January 2005 under a strong (wind speed was about $910 \mathrm{~m} \mathrm{~s}^{-1}$ ) on shore wind. The different arrows point out examples of different temporal scales of WLF, e.g. long term decrease in water level (diurnal change), basin scale oscillation and short term WLF generated by ship waves. The $1 \mathrm{~min}$ running average highlights the basin scale oscillation with a magnitude of about $2 \mathrm{~cm}$ (emphasised by the dashed grey ellipse with arrow)

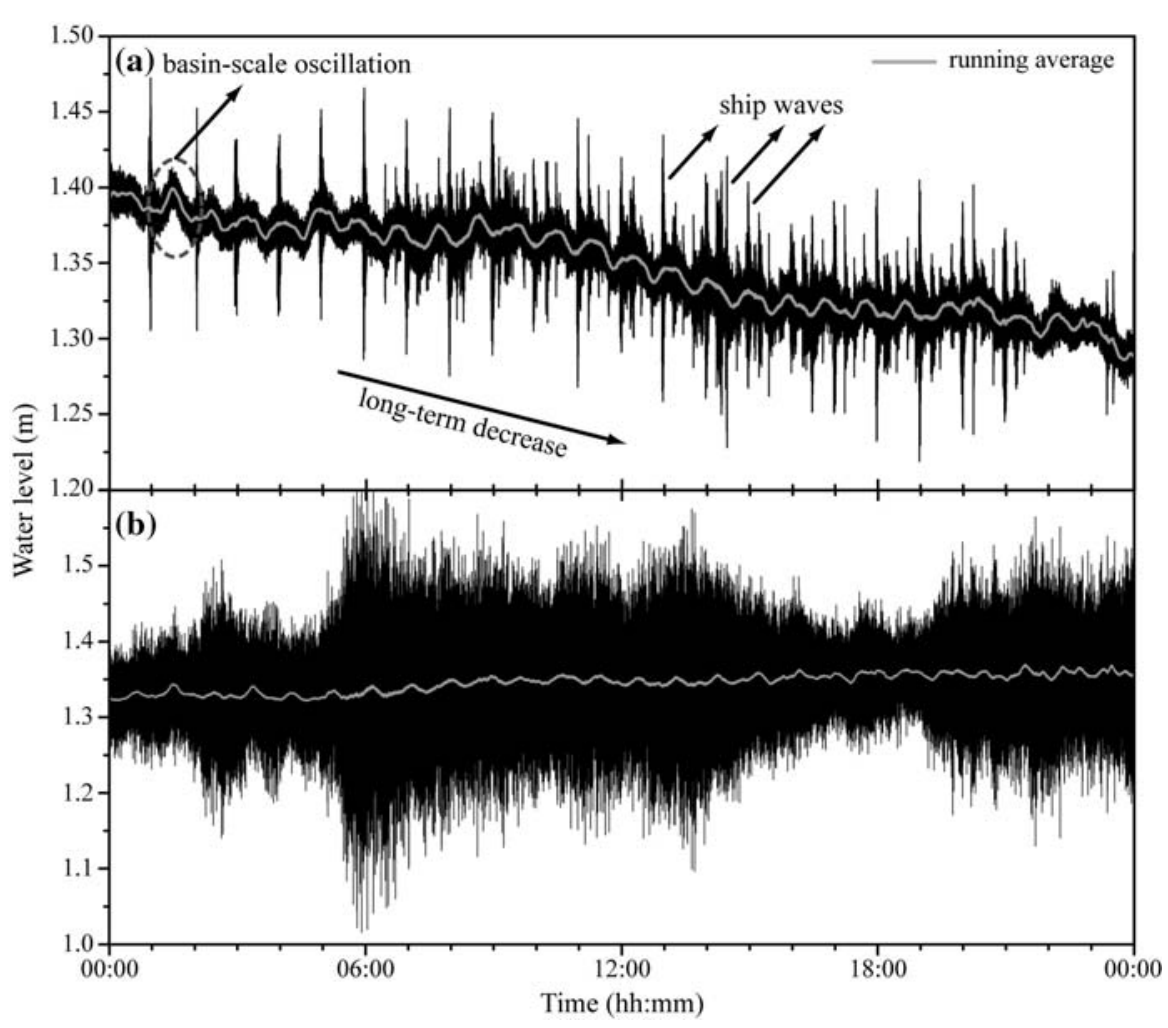


Fig. 2a, b, although the period may differ slightly depending on the actual water level of the lake (Hollan et al., 1981). The vertical displacements of the water surface associated with the first-mode surface seiche are only a few centimetres and were measured to be about $2 \mathrm{~cm}$ at the measuring site LG (Fig. 2a, b). These lake level oscillations are excited by wind forcing at the water surface or due to atmospheric pressure gradients. Power spectra of high-frequency pressure time series show several spectral peaks with periods between minutes and one hour. Numerical calculations suggest that these peaks correspond to level fluctuations due to second, third- or even higher-order modes of basin-scale surface oscillations of Lake Constance (Bäuerle, pers. comm.).

From an ecological perspective, travelling surface gravity waves are probably the most important shortterm WLF. Such waves are generated by wind or by ships and are usually classified as wind waves and ship waves. Both types of waves were measured, characterised and analysed at Lake Constance (Fig. 2a, b; Hofmann et al., 2008). Ship waves cause very harmonic and regular surface oscillation and their periods are determined by their excitation, which is characteristic for each individual ship. The frequency of occurrence and the wave heights of ship waves are highly predictable in time for Lake Constance. They are controlled by the regular sailings of various ferry lines throughout the year with each individual wave group identified as a distinct signal (Fig. 2a; Hofmann et al., 2008). Wind waves in contrast are irregular and are determined by the length of the effective wind fetch and the wind speed, which changes from site to site. Ship waves generated by ferries, passenger ships, or by the recently introduced fast catamaran ferries have wave periods of $2.96 .3 \mathrm{~s}$, characteristic wave heights of $0.040 .5 \mathrm{~m}$ and wave lengths of $1350 \mathrm{~m}$ (assuming deep-water waves); whereas the wave periods, heights and lengths of wind waves are $1.52 .3 \mathrm{~s}$, up to $0.8 \mathrm{~m}$, and $28 \mathrm{~m}$, respectively (Fig. 2a, b; Hofmann et al., 2008). If no wind is present, the wave field is dominated by ship waves (Fig. 2a), which are masked by the higher wind waves during periods of strong on-shore wind (Fig. 2b). Depending on the duration of wind forcing, wind waves can dominate the wave field for hours or even days (Fig. 2b).

\section{Discussion}

Impacts of long-term WLF

Since long-term WLF are associated with large shore line displacements, the major impact of long-term WLF on lake ecosystems is a change in habitat. Long-term WLF flood formerly dry shore areas or expose submerged sediment surfaces to the atmosphere. Thus, long-term WLF play a role in the selection of sessile species adapted to dry or wet conditions. In addition, long-term WLF result in a change of the properties of the sediment surface in the littoral zone, because the grain sizes in the shore region are not homogeneously distributed but change from large to small towards deeper regions of the lake. In the following we provide examples for the range and consequences of long-term WLF.

Based on noble gas concentrations in sediment pore water Brennwald et al. (2004) concluded that the water level of Lake Issyk-Kul, one of the largest and deepest lakes in the world (volume: $1,740 \mathrm{~km}^{3}$, max. depth: $668 \mathrm{~m}$ ) located in Kyrgyzstan, has been at least $250 \mathrm{~m}$ lower during the mid-Holocene than today. As Lake Issyk-Kul is a closed basin lake, its water level is very sensitive to changes in the meteorological conditions. The drop in water level by $250 \mathrm{~m}$ during the mid-Holocene implies a shore line displacement of $2060 \mathrm{~km}$ and a reduction of water volume by more than $40 \%$. During low water level the salinity was more than twice its present value of $6 \%$ as indicated by noble gas data from the pore water (Brennwald et al., 2004). WLF induced salinity changes between $6 \%$ and above $12 \%$ can be expected to have had severe effects on the species composition, because most freshwater animals cannot survive in waters with salinities of more than 10\% (Wetzel, 2001). This long-term WLF had clearly visible consequences for the basin morphology. During low water level, rivers caused large gully erosion especially in the eastern shallow region, which was dry at this time, resulting in channels of $100 \mathrm{~m}$ depth (Tsigelnaya, 1995). Today, these ancient shallow regions are $20 \mathrm{~m}$ below water level and the flooded channels play an important role in the renewal and the oxygenation of the deep water in Lake Issyk-Kul (Peeters et al., 2003). Hence, today's high oxygen levels in the deep water can be considered as an indirect consequence of the longterm WLF. 
Long-term WLF on decadal time scales have been recorded for the Caspian Sea, the largest inland water body (with respect to surface area and volume) on earth. Between 1880 and 1978 the level of the Caspian Sea decreased by $4 \mathrm{~m}$ and then rose again by $2.5 \mathrm{~m}$ within 20 yr. According to Rodionov (1994) the sea level fluctuations of the Caspian Sea are caused by variations in the inflow, which resulted from natural fluctuations of the North Atlantic Oscillation (NAO) and, to a minor extend, by anthropogenic influences, e.g. the use of Volga water for irrigation (Klige \& Myagkov, 1992). The vertical amplitudes of the WLF of the Caspian Sea are small compared to those mentioned above for Lake Issyk$\mathrm{Kul}$, but the associated change in surface area is much higher with about $50,000 \mathrm{~km}^{2}$. The inflow of freshwater related to the water level increase during the 1980s and 1990s caused a significant reduction in vertical mixing, which resulted in nearly anoxic conditions in the deep water (Peeters et al., 2000). The consequence of a long-term increase in water level for internal mixing processes is particularly important in saline lakes, e.g. Mono Lake (Romero \& Melack, 1996) or Caspian Sea (Peeters et al., 2000), because a change in water level is usually associated with freshwater inflow that leads to an increase in water column stability, and thus, hinders convective mixing processes. In freshwater lakes and reservoirs long-term WLF have an impact on vertical mixing only if the level is altered substantially, e.g. if the level is reduced sufficiently that wind forcing or nocturnal convection reaches down to the lake bottom of a formerly dimictic or monomictic lake.

The above examples demonstrate that long-term WLF can influence the oxic state of saline lakes, which in turn affects sediment water exchange and the chemical composition of the deep-water. Longterm WLF have also implications on socio-economic circumstances. The Aral Sea is a very drastic example (Usmanova, 2003). However, in the Caspian Sea the comparatively small decline until 1978 caused rapidly decreasing ground water levels, which resulted in a drastic reduction of agricultural production (Kosarev \& Yablonskaya, 1994). The rising sea level in the 1980s and 1990s destroyed infrastructure built along the shore line during the period of low water level (Dumont, 1995). Furthermore, the strong decline in the abundance of sturgeon in the Caspian Sea during the last decades has been explained by the reduction of appropriate spawning grounds (Khodorevskaya \& Krasikov, 1999). Impacts of long-term WLF on fish reproduction have been demonstrated in Lake Constance as well as in other lakes. The temporal variability of seasonal WLF affects the fish specific substrate availability for spawning, and hence determines egg mortality and breading success (Gafny et al., 1992). Also water birds are affected by longterm WLF at Lake Constance (Werner, pers. comm.). Especially low water levels in spring reduce the availability of appropriate breeding-sites, and hence increase the mortality due to predation. Seasonal or even longer-lasting WLF also cause shifts and variations of the riparian plant community, e.g. diversity, abundance and structure (Kotowski \& Pioŕkowski, 2005). In contrast, flood events as specifically drastic long-term WLF can have severe effects on a former established plant community. Schmieder et al. (2004) has documented the degradation of reed belts after early spring floods at Lake Constance.

\section{Impacts of short-term WLF}

Since short-term WLF do not induce large horizontal shore-line displacements but are accompanied by high current velocities near the sediment (Table 1), their major impact on the lake ecosystem is the imposition of hydrodynamic stress on organisms living in the shore region and on the sediment surface. The hydrodynamic stress affects ecological processes such as competition between individual organisms, short-term production and losses in biofilms and erosion of sediments. The impact of the short-term WLF is, however, variable in strength and time.

Wind and ship waves can be observed throughout the entire year and at any lake shore as long as no ice cover exists. However, wave heights and frequencies can vary substantially due to the different exposure to wind or ship traffic (see section "Short-term WLF"). Particularly affected by short-term WLF are the shallow littoral zones of lakes, even if wave heights are small. Note that the littoral zone is of specific importance to the entire ecosystem because they are characterised by high species diversities and abundances and are important for the reproduction and the life cycle of many fish species.

The availability and intensity of light, as an indispensable resource for primary production of 


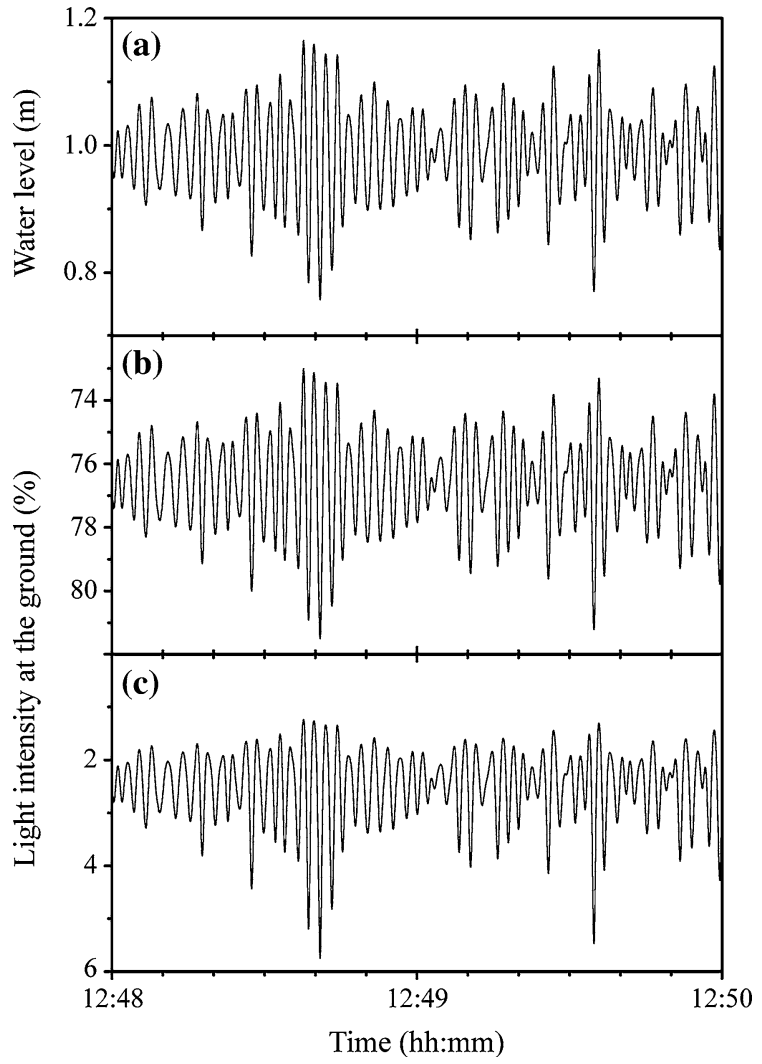

Fig. 3 Wave generated high frequency water level and light fluctuations. (a) Water level fluctuations measured in Lake Constance on 18 September 2005 during a period of strong on shore wind. Light intensity fluctuations at the ground are given as percents of the incoming light intensity at the water surface. (b) For clear water. The light intensity was calculated for an exponential decay of light with depth using an average extinction coefficient $\left(K_{\mathrm{d}}\right)$ of $0.27 \mathrm{~m}^{-1}$ representative for pelagic waters (IGKB, 2002). (c) Considering the additional shading effect due to resuspended particles in the shallow littoral ( $\left.K_{\mathrm{dss}} \quad 0.27+0.025^{*} C_{\mathrm{ss}}\right)$ (van Duin et al., 2001). The particle concentration $C_{\mathrm{ss}}$ was measured to $140 \mathrm{mg}^{-1}$ during the time of measurement

phytoplankton in the water column or of periphyton on stones and on the sediment surface, is affected by short-term WLF. Fluctuations of the under water light intensity associated with short-term WLF due to wind waves are exemplified in Fig. 3. During on-shore wind on 18 September 2005, short-term WLF (wind waves) with a period of about $2 \mathrm{~s}$ and wave heights between 0.1 and $0.4 \mathrm{~m}$ were observed (Fig. 3a) and caused light intensity fluctuations at the ground of $28 \%$, based on exponential light decay with an average extinction coefficient $\left(K_{\mathrm{d}}\right)$ of $0.27 \mathrm{~m}^{-1}$ representative for pelagic waters (Fig. 3b; IGKB,

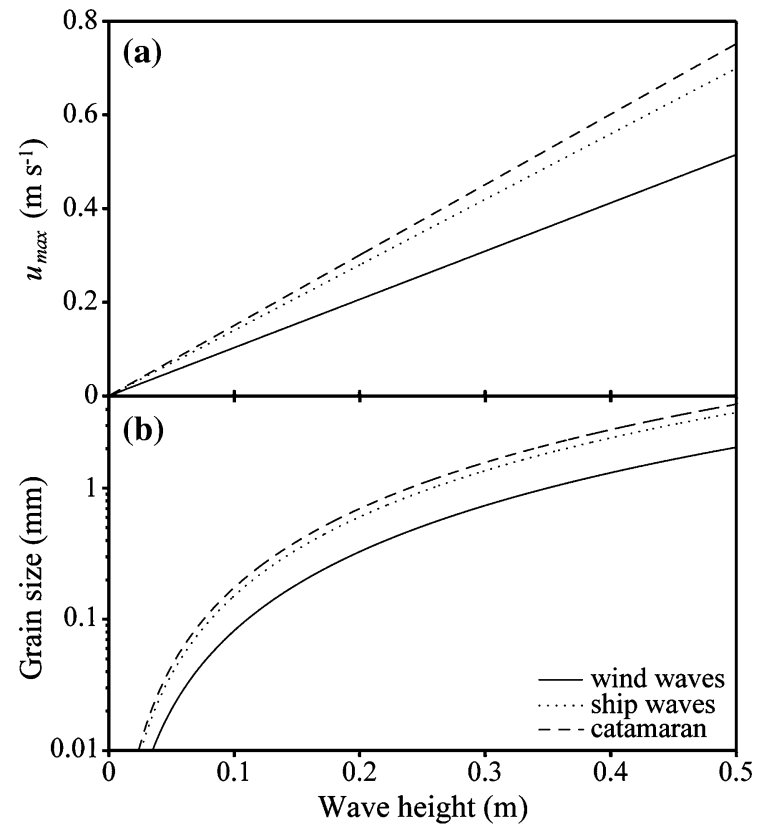

Fig. 4 Potential forcing of short term WLF in the littoral zone. (a) Maximum wave generated near bottom current velocity $\left(u_{\max }\right)$ at $1 \mathrm{~m}$ water depth as a function of wave height and wave period $(T)$ for wind generated $\left(\begin{array}{ll}T & 2 \mathrm{~s}\end{array}\right)$ and ship generated ( $\left.\begin{array}{lll}T & 3.3 \text { and } T \quad 6.3 \mathrm{~s}\end{array}\right)$ waves, respectively. (b) Minimum wave heights required for the remobilisation of particles of different grain sizes as a function of wave period (as under (a)) at the water depth of $1 \mathrm{~m}$

2002). The remaining mean light intensity at 1-m water depth is then about $77 \%$ of the incoming light at the water surface. Fluctuations of the under waterlight intensity can be further amplified by wave focussing which increases the light intensity within milliseconds up to five times of the mean value (Dera \& Gordon, 1968; Stramski \& Legendre, 1992; Schubert et al., 2001; Hofmann et al., in press). In the shallow littoral the observed surface waves induce resuspension of particles with grain sizes up to $1 \mathrm{~mm}$ at 1-m water depth (Fig. 4b). The increased backscatter of light due to suspended particles leads to intense shading and reduces dramatically the light intensity at the sediment surface down to $23 \%$ of the incoming light at the water surface (Fig. 3c; van Duin et al., 2001). During an individual wind event, which can last for more than one day, primary production can be reduced or even inhibited (van Duin et al., 2001). In the aftermath of such events the remobilised and suspended particles settle down and cover biofilms and periphyton on stones. The frequency of 
Fig. 5 Sketch of a typical prealpine shore line for different water levels. The sketch indicates the interactions and impacts of long term versus short term WLF on remobilisation, resuspension, transport and distribution of particles in the littoral zone

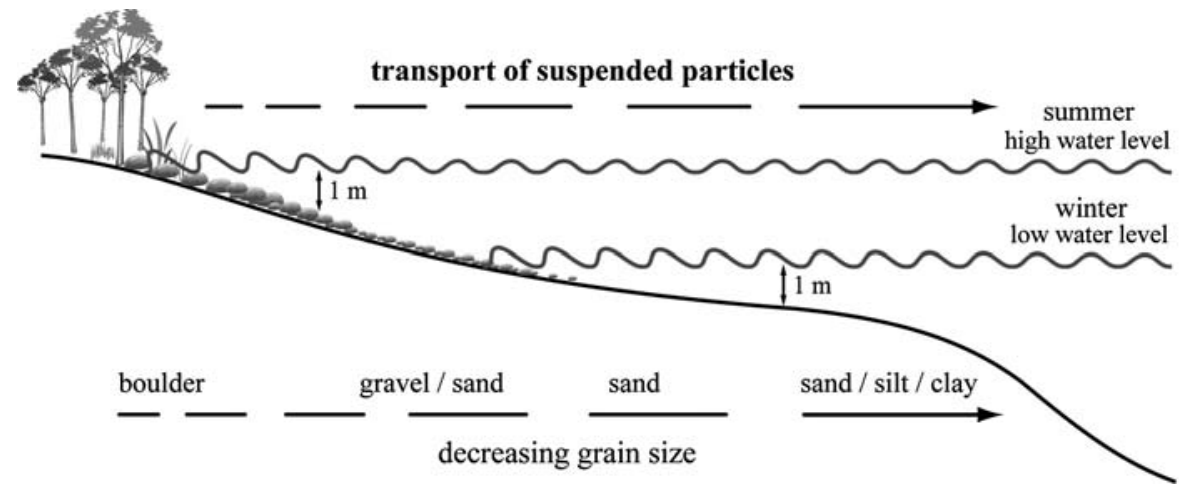

occurrence of strong wind events determines the density and appearance of periphyton in the shallow littoral, and hence indicates the habitat exposure to hydrodynamic disturbances (Cattaneo, 1990; Airoldi \& Cinelli, 1997; Francoeur \& Biggs, 2006).

Also higher developed organisms are influenced by hydrodynamic stress due to waves. The comparison of zoobenthos and fish communities at surface wave exposed and non-exposed shores revealed the different sensitivity, selectivity and species composition of these communities in many studies (Clark, 1997; Abdallah \& Barton, 2003; Eggleton et al., 2004).

The high productivity of the shallow littoral zone results in intense microbial decomposition rates of organic material (Wetzel, 2001). The sequence of production and decomposition is forced by boundary conditions as nutrient availability or the renewal of diffusive gradients for deoxidisation of organic material to carbon dioxide and methane. High current velocities and strong turbulence associated with shoaling surface waves enhance solute diffusion across the sediment water interface (Lorke et al., 2003), lead to remobilisation of particles and reallocation of sediment layers (Fig. 4b), and hence reset the adjusted gradients due to increased pore-water exchange (Precht \& Huettel, 2003; Precht et al., 2004). An important implication is the rapid release of recycled nutrients and methane (Li et al., 1997; Asmus et al., 1998; Heyer \& Berger, 2000; Schulz et al., 2001).

Interacting long- and short-term WLF

The discussion above exemplifies the impacts of WLF on abiotic or biotic processes at very different temporal scales. In the following we demonstrate that the interaction between different time scales, i.e. the interaction between long-term and short-term WLF, has important ecological consequences.

With respect to WLF, Lake Constance can be considered to represent natural conditions typical for prealpine lakes before their regulation. The seasonal change in water level is about $2 \mathrm{~m}$. During summer, the entire shore region up to the very shallow littoral is covered with water, whereas in winter the littoral is reduced to a very narrow zone along the steep slope of the lake (Fig. 5). At low water levels the shallow littoral is not submersed, and hence widely exposed to atmospheric decomposition, weathering and deflation. These processes change the former sediment composition, where rock will break up and fine particles will be blown away or deposited.

Waves impose hydrodynamic shear stress on the lake bottom and initiate sediment remobilisation, resuspension and transport due to background currents in cross- or along-shore direction. Remobilisation of particles at the sediment surface depends on water depth, grain size, wave height and wave period. The maximum near-bottom wave-generated current velocity $u_{\max }$ at the sediment surface at $1-\mathrm{m}$ water depth was estimated for wave heights of $00.5 \mathrm{~m}$ and for wave periods of 2, 3.3 and $6.3 \mathrm{~s}$ (Eq. 1, Fig. 4a). These represent typical values at Lake Constance for wind waves, for ship waves generated by permanent ferries or passenger ships and for ship waves generated by fast catamaran ferries, respectively (Hofmann et al., 2008). Long-periodic ship waves induce much higher velocities at the ground and remobilise much larger particles in comparison to wind waves with the same height (Fig. 4a, b). For example, with a wave height of $0.2 \mathrm{~m}$, wind waves remobilise particles of 
grain sizes up to $0.3 \mathrm{~mm}$, whereas ship waves are able to remobilise particles with grain sizes up to $0.6 \mathrm{~mm}$. This demonstrates the importance of ship waves for sediment remobilisation at exposed shores. Although wind and ship waves occur throughout the whole year, they develop their main impact at different sections of the littoral zone due to seasonal, long-term WLF (Fig. 5). Due to the shore line displacement by seasonal WLF the substrate at the ground at shallow depths varies substantially over the year. During summer, when the water level is high, the substrate consists mainly of boulders, cobbles, gravel and sand. In winter, the substrate at low water levels is formed by much smaller particles like fine sand, silt and clay (Fig. 5). Therefore, the same wind and ship waves result in much higher rates of remobilisation, resuspension and transport into the pelagic zone during winter than during summer (Figs. 4b, 5). The interaction between seasonal WLF (long-term WLF) and waves (short-term WLF) is a permanent process leading to a continuously decreasing grain size distribution from boulders to clay in off-shore direction (Fig. 5). Over the decades, small particles that can be remobilised by waves, are transported to deeper zones. At the site LG the lake floor falls off gently from the shore line towards the open water. At a water depth of about $12 \mathrm{~m}$ below the average annual minimum water level, the slope of the lake floor increases significantly, thus, forming the socalled "Haldenkante". The location of the "Haldenkante" and the presence of the fine-grained sediments at this location reflect the combined action of longand short-term WLF in Lake Constance.

The export of fine particles from the littoral zone to the pelagic, and thus, erosion is expected to increase with the decreasing mean water levels observed during the recent past. In combination with the increasing exposure of the shore region to ship waves due to increasing ship traffic on Lake Constance, i.e. due to passenger ships and the recently introduced fast catamaran ferries, erosion of the shore region may be even more dramatic. Observations of divers investigating oak poles in the context of maritime archaeology suggest that many historic and archaeologically important under water heritages like pile dwellings are more and more threatened by the interaction between surface waves and long-term WLF, i.e. previously sand covered sites became uncovered by erosion and are now directly exposed to oxygen rich water, and thus, faster biological decomposition (Bürgi \& Schlichterle, 1986; Körninger, 2005).

\section{Conclusions}

WLF in lakes exist on temporal scales from seconds to even hundreds of years (Table 1). The ecological impact of WLF depends on the time scale of the level fluctuation and can be amplified by the combined action of long- and short-term WLF. In this paper, WLF are classified as long- and short-term WLF based on the generation mechanism of the WLF with long-term WLF being the consequence of changes in the hydrologic conditions and short-term WLF being the result of hydrodynamic processes, namely waves and basin-scale oscillations.

Long-term WLF can have large amplitudes and induce a slow shore-line displacement of metres or even kilometres, whereas the immediate physical forcing due to currents is negligible. Although the physical forcing of long-term WLF is low, the impacts on the entire ecosystem can be versatile: long-lasting changes in habitat availability for organisms adapted to terrestrial and aquatic conditions, lake salinity, vertical mixing, deep water renewal, or oxygen supply to the deep water. In the case of Lake Constance, the annual mean water level has changed only very little over the last $189 \mathrm{yr}$ and also the interannual variation of the annual mean water level did never exceed $0.75 \mathrm{~m}$. However, seasonal changes in water level can reach up to more than $3 \mathrm{~m}$, and thus, cause shore-line displacements of up to hundreds of metres. Hence, seasonal WLF are probably the most important component of long-term WLF affecting competition and survival of species in the littoral zone.

Compared to the seasonal WLF, short-term WLF have much smaller amplitudes and do not significantly displace the boundary between the terrestrial and aquatic habitat but provide high amounts of mechanical energy to abiotic processes, e.g. remobilisation and resuspension of particles, sediment transport, release of nutrients and methane and abrasion of biofilms. The change in abiotic habitat conditions is often followed by changed biotic processes, e.g. resuspended and settled particles reduce the availability of light for photosynthesis, 
which then result in a decreased growth of phytoplankton and biofilms.

Although the forcing of long- and short-term WLF is different the interaction of both can cause additional consequences to those resulting from the individual process themselves. Long-term WLF change the habitat exposed to the physical stress provided by short-term WLF. Specifically, shore morphology and sediment grain size distribution are the result of a continuous interplay between short- and long-term WLF, the former providing the energy for erosion the latter determining the section of the shore exposed to the erosive power.

Acknowledgements We thank Georg Heine and his colleagues from the electronic and mechanical workshop at the University of Konstanz for technical assistance and the development of the pressure sensors. We gratefully acknowledge the help of the technical staff at the Limnological Institute and many students during fieldwork and data analysis. We thank the two anonymous referees whose valuable comments improved the manuscript. The gauge Konstanz water level time series between 1817 and 2005 was provided by the State Institute for Environment, Measurements and Nature Conservation Baden Württemberg (LUBW). This work was supported by the German Research Foundation (DFG) within the framework of the Collaborative Research Centre 454 "Littoral Zone of Lake Constance".

\section{References}

Abdallah, A. M. \& D. R. Barton, 2003. Environmental factors controlling the distributions of benthic invertebrates on rocky shores of Lake Malawi, Africa. Journal of Great Lakes Research 29(suppl. 2): 202215.

Airoldi, L. \& F. Cinelli, 1997. Effects of sedimentation on subtidal macroalgal assemblages: an experimental study from a mediterranean rocky shore. Journal of Experi mental Marine Biology and Ecology 215: 269288.

Asmus, R. M., M. H. Jensen, K. M. Jensen, E. Kristensen, H. Asmus \& A. Wille, 1998. The role of water movement and spatial scaling for measurement of dissolved inor ganic nitrogen fluxes in intertidal sediments. Estuarine, Coastal and Shelf Science 46: 221232.

Bourne, J. K., K. Joel \& G. Ludwig, 2005. Eccentric Salton Sea. National Geographic Magazine 207: 88107.

Braun, E. \& K. Schärpf, 1990. Internationale Bodensee Tie fenvermessung. IGKB Internationale Gewässerschutzkom mission für den Bodensee: 98 .

Brennwald, M. S., et al., 2004. Atmospheric noble gases in lake sediment pore water as proxies for environmental change. Geophysical Research Letters 31: L04202.

Brown, E., A. Colling, D. Park, J. Phillips, D. Rothery \& J. Wright, 2005. Waves, Tides and Shallow Water Pro cesses, 2nd edn. Butterworth Heinemann, Boston.

Bürgi, J. \& H. Schlichterle, 1986. Gefährdete Ufersiedlungen am Bodensee. Archäologie der Schweiz 9: 3441.
Cattaneo, A., 1990. The effect of fetch on periphyton spatial variation. Hydrobiologia 206: 110.

Clark, B. M., 1997. Variation in surf zone fish community structure across a wave exposure gradient. Estuarine, Coastal and Shelf Science 44: 659674.

Coe, M. T. \& J. A. Foley, 2001. Human and natural impacts on the water resources of the Lake Chad basin. Journal of Geophysical Research 106: 33493356.

Coops, H., M. Beklioglu \& T. L. Crisman, 2003. The role of water level fluctuations in shallow lake ecosystems workshop conclusions. Hydrobiologia 506: 2327.

Dera, J. \& H. R. Gordon, 1968. Light fluctuations in the photic zone. Limnology and Oceanography 13: 697699.

Dumont, H., 1995. Ecocide in the Caspian Sea. Nature 377: 673674.

Eggleton, M. A., K. B. Gido, W. J. Matthews \& G. D. Schnell, 2004. Assessment of anthropogenic influences on littoral zone aquatic communities of Lake Texoma, Oklahoma Texas, USA. Ecohydrology and Hydrobiology 4: 103117.

Emery, W. J. \& R. E. Thomson, 2001. Data analysis methods in physical oceanography, 2nd edn. Elsevier Science, Amsterdam.

Eriksson, B. K., A. Sandström, M. Isæus, H. Schreiber \& P. Karås, 2004. Effects of boating activities on aquatic vegetation in the Stockholm archipelago, Baltic Sea. Estuarine, Coastal and Shelf Science 61: 339349.

Erm, A. \& T. Soomere, 2006. The impact of fast ferry traffic on underwater optics and sediment resuspension. Oceanolo gia 48(suppl.): 283301.

Fenton, J. D. \& W. D. McKee, 1990. On calculating the lengths of water waves. Coastal Engineering 14: 499513.

Francoeur, S. \& B. Biggs, 2006. Short term effects of elevated velocity and sediment abrasion on benthic algal commu nities. Hydrobiologia 561: 5969.

Gafny, S., A. Gasith \& M. Goren, 1992. Effect of water level fluctuation on shore spawning of Mirogrex terraesanctae (Steinitz), (Cyprinidae) in Lake Kinneret, Israel. Journal of Fish Biology 41: 863871.

Guganesharajah, K. \& E. M. Shaw, 1984. Forecasting water levels for Lake Chad. Water Resources Research 20: 10531065.

Hallermeier, R. J., 1980. Sand motion initiation by water waves: two asymtotes. Journal of the Waterway, Port, Coastal, and Ocean Division 106: 299318.

Heyer, J. \& U. Berger, 2000. Methane emission from the coastal area in the Southern Baltic Sea. Estuarine, Coastal and Shelf Science 51: 1330 .

Hofmann, H., A. Lorke \& F. Peeters, 2008. The relative importance of wind and ship waves in the littoral zone of a large lake. Limnology and Oceanography 53: 368380.

Hofmann, H., A. Lorke \& F. Peeters, in press. Wave induced variability of the underwater light climate in the littoral zone. Verhandlungen der Internationalen Vereinigung für Theoretische und Angewandte Limnologie 30(part 4).

Hollan, E., D. B. Rao \& E. Bäuerle, 1981. Free surface oscillations in Lake Constance with an interpretation of the "Wonder of the Rising Water" at Konstanz in 1549. Meteorology and Atmospheric Physics 29: 301325.

Hunt, P. C. \& J. W. Jones, 1972. The effect of water level fluctuations on a littoral fauna. Journal of Fish Biology 4: 385394. 
IGKB, 2002. Tolerierbare Phosphor Fracht des Bodensee Obersees. In Bührer, H. (ed.), Bericht der Internationalen Gewässerschutzkommission für den Bodensee 54: 81.

Jöhnk, K. D., D. Straile \& W. Ostendorp, 2004. Water level variability and trends in Lake Constance in the light of the 1999 centennial flood. Limnologica 34: 1521.

Khodorevskaya, R. P. \& Y. V. Krasikov, 1999. Sturgeon abundance and distribution in the Caspian Sea. Journal of Applied Ichthyology 15: 106113.

Klige, R. K. \& M. S. Myagkov, 1992. Changes in the water regime of the Caspian Sea. GeoJournal 27: 299307.

Körninger, J., 2005. Unterwasserarchäologie am Überlinger See. NAU Nachrichtenblatt Arbeitskreis Unterwasserarchäolo gie 11/12: 6370 .

Kosarev, A. N. \& E. A. Yablonskaya, 1994. The Caspian Sea. SPB Academic Publishing, The Hague.

Kotowski, W. \& H. Pioŕkowski, 2005. Competition and suc cession affecting vegetation structure in riparian environments: implications for nature management. Eco hydrology and Hydrobiology 5: 5157.

Kundu, P. K. \& I. M. Cohen, 2002. Fluid Mechanics. Aca demic Press, London.

Lerman, A., D. M. Imboden \& J. R. Gat, 1995. Physics and Chemistry of Lakes, 2nd edn. Springer, Berlin.

Li, Y., A. J. Mehta, K. Hatfield \& M. S. Dortch, 1997. Mod ulation of constituent release across the mud water interface by water waves. Water Resources Research 33: 14091418.

Lorke, A., B. Müller, M. Maerki \& A. Wüest, 2003. Breathing sediments: the control of diffusive transport across the sediment water interface by periodic boundary layer tur bulence. Limnology and Oceanography 48: 20772085.

Luettich R. A. Jr., D. R. F. Harleman \& L. Somlyody, 1990. Dynamic behavior of suspended sediment concentrations in a shallow lake perturbed by episodic wind events. Limnology and Oceanography 35: 10501067.

Luft, G. \& G. van den Eertwegh, 1991. Long term changes in the water level of Lake Constance and possible causes. Hydrology of Natural and Manmade Lakes. In Schiller, G., Lemmelä, R. \& Spreafico, M. (eds.). IAHS Press, Wallingford, England: 3144.

Luft, G. \& H. Vieser, 1990. Veränderung der Bodensee Wasserstände von 1887 bis 1987. Deutsche Gewässerkun dliche Mitteilungen 34: 148156.

McGowan, S., P. R. Leavitt \& R. I. Hall, 2005. A whole lake experiment to determine the effects of winter droughts on shallow lakes. Ecosystems 8: 694708.

Mortimer, C. H., 1974. Lake hydrodynamics. Mitteilungen der Internationalen Vereinigung für Theoretische und Ange wandte Limnologie 20: 124197.

Naselli Flores, L. \& R. Barone, 2005. Water level fluctuations in Mediterranean reservoirs: setting a dewatering thresh old as a management tool to improve water quality. Hydrobiologia 548: 8599.

Peeters, F., D. Finger, M. Hofer, M. Brennwald, D. M. Liv ingstone \& R. Kipfer, 2003. Deep water renewal in Lake
Issyk Kul driven by differential cooling. Limnology and Oceanography 48: 14191431.

Peeters, F., et al., 2000. Analysis of deep water exchange in the Caspian Sea based on environmental tracers. Deep Sea Research Part I 47: 621654.

Precht, E., U. Franke, L. Polerecky \& M. Huettel, 2004. Oxygen dynamics in permeable sediments with wave driven pore water exchange. Limnology and Oceanogra phy 49: 693705.

Precht, E. \& M. Huettel, 2003. Advective pore water exchange driven by surface gravity waves and its ecological impli cations. Limnology and Oceanography 48: 16741684.

Rodionov, S. N., 1994. Global and Regional Climate Interac tion: The Caspian Sea Experience. Kluwer Academic Publisher, Dordrecht.

Romero, J. R. \& J. M. Melack, 1996. Sensitivity of vertical mixing in a large saline lake to variations in runoff. Limnology and Oceanography 41: 955965.

Scheifhacken, N., 2006. Life at Turbulent Sites: Benthic Communities in Lake Littorals Interacting with Abiotic and Biotic Constraints. $\mathrm{PhD}$ Thesis, University of Konstanz.

Schmieder, K., M. Dienst, W. Ostendorp \& K. Jöhnk, 2004. Effects of water level variations on the dynamics of the reed belts of Lake Constance. Ecohydrology and Hydro biology 4: 469480.

Schubert, H., S. Sagert \& R. M. Forster, 2001. Evaluation of the different levels of variability in the underwater light field of a shallow estuary. Helgoland Marine Research 55: 1255.

Schulz, M., E. Faber, A. Hollerbach, H. G. Schroeder \& H. Guede, 2001. The methane cycle in the epilimnion of Lake Constance. Archiv für Hydrobiologie 151: 157176.

Soomere, T., 2005. Fast ferry traffic as a qualitatively new forcing factor of environmental processes in non tidal sea areas: a case study in Tallinn Bay, Baltic Sea. Environ mental Fluid Mechanics 5: 293323.

Stephens, D. W., 1990. Changes in lake levels, salinity and the biological community of Great Salt Lake (Utah, USA), 1847 1987. Hydrobiologia 197: 139146.

Stramski, D. \& L. Legendre, 1992. Laboratory simulation of light focusing by water surface waves. Marine Biology 114: 341348 .

Tsigelnaya, I. D., 1995. Issyk Kul Lake. In Maudych, A. F. (ed.), Enclosed seas and Large Lakes of Eastern Europe and Middle Asia. SPB Academic Publishing, Amsterdam: 199229.

Usmanova, R. M., 2003. Aral Sea and sustainable develop ment. Water Science and Technology 47: 4147.

van Duin, E. H. S., et al., 2001. Modeling underwater light climate in relation to sedimentation, resuspension, water quality and autotrophic growth. Hydrobiologia 444: 2542 .

Wetzel, R. G., 2001. Limnology Lake and River Ecosystems. Academic Press, London.

Zavialov, P. O., et al., 2003. Hydrographic survey in the dying Aral Sea. Geophysical Research Letters 30: 1659. 